\title{
OJED
}

Volume 6, Issue 1 (2021), pp. 52-59

Journal of School Administration Research and Development ISSN: 2470-8496 Print/ ISSN: 2470-850X Online

ojed.org/jsard

\section{Developing the Leadership Capacity of Teachers: Theory to Practice}

\author{
M. Adam Carswell \\ St. George's University, Grenada, West Indies
}

\begin{abstract}
Today's school leaders need to prioritize the development of leadership capacity in classroom teachers. Leadership development commonly involves either teachers expressing an interest in leadership or school leaders finding talent in those teachers whom they believe have the capacity to grow into formal leadership roles. School leaders must be able to recognize teachers who overflow with terrific ideas and leadership potential and those who are less likely to self-identify as leadership candidates. However, as a school administrator desires to cultivate leadership capacity in teachers, he or she must devise a plan. To accomplish this task effectively, best practices and theory must be utilized. Therefore, this essay addresses the use of best practices as identified in literature to promote a positive school climate, collaboration, motivation, reflective practice, and teacher leadership development.
\end{abstract}

Keywords: leadership shortage, leadership development, teacher leader, school climate, teacher motivation, teacher mentorship, leader mentorship, teacher passion

Leadership development commonly involves either teachers expressing an interest in a formal leadership role and selfidentifying or school leaders finding talent in those whom they believe have the capacity to grow into more formal leadership roles. Although there is some merit to these approaches, there is also the risk of missing quiet and thoughtful teachers who overflow with terrific ideas and leadership potential, but who are less likely to self-identify as leadership candidates. Furthermore, these unidentified talents can restrict teacher leadership development to a chosen few rather than allowing each member of a school's faculty the opportunity to grow and develop leadership skills at their own rate and for their own personal growth or interest. Preskill and Brookfield (2009) suggested that effective leaders provide others with "opportunities to employ fully their experience and talents" (p.4) in a trusting environment that minimizes risk to the leader-in-training. By encouraging teachers to take risks and venture into unchartered waters outside the comfortable domain of their classrooms, leaders are able to share valuable lessons in leadership while simultaneously enriching the culture and climate, improving school leaders' and students' experiences, as well as fortifying the mission of the school organization as a whole. This, in turn, enriches leaders' own experience by creating a sense of fulfillment that comes through watching a teacher grow and develop into the kind of leader they can become.

This best practice essay reviews current literature regarding school climate, collaboration, teacher motivation, and teacher leadership development and then applies that theory to practice through related vignettes based on the author's twodecades of learning while leading. It is the intent that both the best practices and vignettes will aid in emphasizing the importance of building trusting and authentic relationships with teachers to foster teacher leadership and opportunities. This can only be accomplished, however, in schools where leaders intentionally build meaningful relationships with teachers, create positive and joyful school climates, foster and model collaboration, understand what motivates teachers to grow professionally, and teach and reflect upon real-world experiences. The Developing Teacher Leadership Model (Figure 1) will be used to discuss best practices in theory and practice throughout this essay. 


\section{Figure 1}

\section{Developing Teacher Leadership}

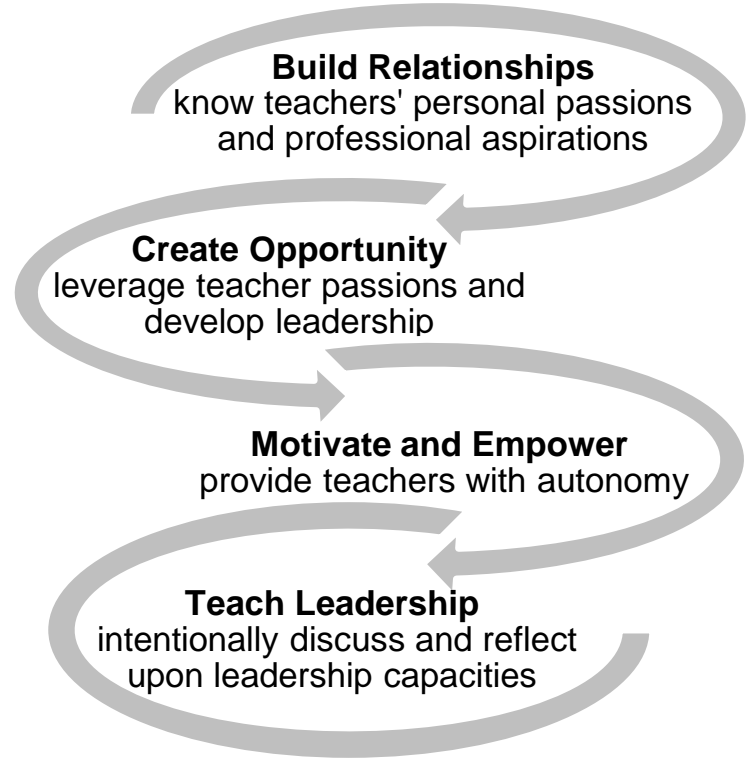

\section{BUILDING RELATIONSHIPS: THE KEY TO POSITIVE SCHOOL CLIMATE}

When leaders build relationships with teachers, they become privy to the unique attributes of teachers by learning answers to questions such as these:

- Why did you become a teacher?

- What excites you about the work you do with students?

- What passions, hobbies, sports, or pastimes keep you busy at home?

- Who has inspired you personally and in your work as an educator?

- What scares you or keeps you up at night?

- Where do you see yourself in the future? What dreams do you have?

- What influences the lens through which you see the world?

- What resources can I provide, or barriers can I remove, to best support you?

- How can you enhance our school and advance our shared mission?

Knowing teachers - really knowing them - positions leaders to promote growth and help teachers to achieve their personal and professional aspirations, while at the same time advancing the school's mission.

School administrators must recognize teachers who inspire students to be happy to attend school because of improved learning and success in school (Höög \& Olofsson, 2005; Ludwick, 2006; Sahin, 2011; Schindler et al, 2016). This includes, for example, teachers who create the weather in their classrooms: whether a dark and stormy night or a bright and sunny day. As school administrators and teachers develop congenial relationships, teachers embrace a sense of independence to think freely, support one another, and feel connected to something bigger than themselves. This creates a synergistic sense of purpose where faculty feel a sense of collective accomplishment, satisfaction, and joy that better enables the team to meet objectives, primarily the success of students. In theory and practice, this synergy, according to Ludwick (2006), stemmed directly from the relationships established by team members: an intricate and fragile balance that must be maintained, developed, and cultivated by the team leader. Ludwick purported that two important factors contribute to synergy within a team: diversity of talent and a unified commitment to a shared mission. Principals who engender confidence in the school's faculty and staff by building a culture conducive to growth toward a shared vision or set of goals or objectives tend to be more successful in engaging teachers in the advancement of the school's mission. In addition, Sahin (2011)described the 
positive and significant correlation that exists between the principal's leadership style and school climate and that a positive school climate enhances the teaching and learning that takes place within a school.

\section{Vignette 1: Forging Authentic Relationships}

It is important for school leaders to very intentionally strive to forge authentic relationships with their teaching staff. As a new school leader 14 years ago, I had no idea how working relationships could be so incredibly important. Not only does authentic and intentional relationship building enhance the climate of the school, but also it ignites teachers' intrinsic motivation to perform their best. In my first year as a principal at a small, independent K-8 school of 500 students, I came to know a particularly creative kindergarten teacher. She had a zeal for all things crafty, but especially knitting. As she tended to do, this kindergarten teacher sprung into my office sporting one of her hand-sewn, colorful, and eclectic outfits that her five-year old students and colleagues had come to love, with an article in her hand. From this article, the teacher shared about the importance of developing graphomotor skills in young children - she proclaimed that development of fine motor dexterity pays great dividends in children's overall academic success. In contrast, she explained that deprivation of the opportunity to develop these skills can have negative implications for children's fine motor skill development. I was impressed, so we worked in tandem to review research, and develop standards, bring her colleagues into the loop, and negotiate the logistics of procuring knitting needles, yarn, and other materials. Finally, we communicated this new learning strategy and its rationale to the parents of our youngest students.

By leveraging this young and eager teacher's unique talent, boundless energy and excitement was created in the early childhood wing, an extraordinary learning opportunity was experienced by the students, and a platform through which teacher leadership capacity was intentionally developed was introduced. With encouragement and continued mentorship, this young teacher grew to become a savvy and influential informal leader in the early childhood team. Furthermore, she developed key leadership capacities that played an important role in helping her to achieve her professional aspirations.

\section{CREATING OPPORTUNITY THROUGH COLLABORATION AND MODELLING}

Given that followers will typically fall in line with whatever tone a leader sets, it is imperative that leaders model collaboration. Sahin (2011) suggested that the school principal is the primary role model for teachers and students when it comes to making improvements, being receptive and collegial, acting courageously, and collaborating with others. People are more collaborative and creative when they see their leaders modeling the practice, and as such it is essential for leaders to develop a culture of collaboration in which they actively take part. The optics of school leaders openly collaborating as equal colleagues with faculty creates transparency and reflection, which establishes an overarching community culture of educators who lead because they understand how to learn rather than because they simply possess more implicit knowledge (Ontario Ministry of Education, 2014). With regard to deliberately developed organizations, Kegan et al. (2013) explained, "These organizations understand that only through membership in workplace communities in which individuals are deeply valued as individual human beings, constantly held accountable, and engaged in real and sustained dialogue can growth happen for individuals" (Kegan, Lahey, Fleming, Miller, and Markus, 2013, p.10). Collaboration is a critical component for creating and maintaining positive school climates that are conducive to teacher leadership development.

These conditions can only be created when leaders deliberately create a joyful and engaging school climate where expectations are clearly articulated and closely monitored (Carswell, 2018). Not only should faculty and administration intentionally allot time in their schedules for reflection and collaboration, they should also ensure proximation to one another is such that spontaneous dialogue and discussion can easily occur (Hord, 2009). Collaborative leaders are in a constant state of learning, sharing ideas and perspectives with and from colleagues. Modelling lifelong learning for teachers and students is another critical responsibility school leaders must embrace with intentionality. Blurring the lines between the teacher and learner and the leader and follower creates trust, transparency, and an ongoing focus on growth and development for both the individual and the organization.

\section{Vignette 2: Modeling and Mentorship: A Recipe for Inspiration}

Leaders who value the ideas and opinions of others not only engage colleagues in collaboration and demonstrate distributive leadership, but they also foster effective leadership modeling and mentorship to aspiring future leaders. I have been incredibly fortunate as a teacher and school leader to have some incredible mentors along the way. On several occasions, my mentors brought me in on meetings, tasked me as chair of a committee, or sat me down and shared perspectives that I would not necessarily have had the opportunity to consider from the role of a classroom teacher. While 
teaching grade five, I was privileged to work alongside two incredible school leaders who encouraged me to consider school leadership as the next step in my professional path. In addition, they also created a pseudo leadership role for me to hone my skills under their mentorship. Apart from my assigned menial management duties, my school leaders brought me from behind the curtains and discussed strategies and collaboration around teacher development, curricular improvement, calendar and event planning, student concerns, and even parent issues. As they asked my perspective, I responded with a context that I never could have offered as a classroom teacher.

I feel gratified for the opportunity the two administrators provided for a young teacher like me to glimpse into the life of a school leader - an experience that frightened me and excited me in equal measures. As a fifth-grade teacher, I was mentored and pushed beyond my comfort zone, supported in my growth, and motivated to perform at my best. I have since been privileged to lead three very different elementary schools, each with colleagues and mentors who initiated a variety of approaches and perspectives that have served as the primary influence in shaping the leader I am today. My professional life as a school administrator is due to the leadership capacity that was cultivated in me as a classroom teacher through theory and best practices modeled by seasoned school leaders. Their inspirational leadership motivated me to continually grow, learn, and hone my craft as a school leader.

\section{MOTIVATION, EMPOWERMENT, AND AUTONOMY}

Leaders who model and encourage collaboration and autonomy also motivate and empower teachers to achieve and perform at their best. This often translates into innovation, creativity, and enhanced teacher experiences that result in leadership qualities. Teachers often only strive to improve their practice, take on more responsibility, and engage in leadership development if they are intrinsically motivated to do so. It is important that school leaders understand the significant influence they have on the dedication and engagement of teachers. When individuals are intrinsically motivated, they are more effective and contribute more meaningfully toward the attainment of the organization's mission (Bayler, \& Özcan, 2012; Sagnak, 2016; Seipert \& Baghurst, 2014; Shwu Ming, 2015).

Teachers' perceptions of leadership behaviors concerning building vision, intellectual stimulation, and innovative climate are all factors of potential teacher leadership qualities. Bayler and Ozcan asserted that "transformational behaviors of school principals were significantly related to collective teacher efficacy" (2012, p. 118). Teachers must be empowered, regarded as professionals, and provided with a degree of autonomy, as teachers' willingness to go above and beyond the call of duty is strongly correlated to elevated levels of intrinsic motivation. These factors are also deemed essential for classroom effectiveness, school improvement, and the development of teacher leaders (Shwu Ming, 2015). Participatory decision making positively impacts organizational outcomes by increasing teacher motivation. Leaders who consult faculty, ask for suggestions, and consider the opinions of others have greater success in creating positive school climates, which leads to teacher leadership development (Sagnak, 2016). Seipert and Baghurst (2014) posited that today's younger generation of educators prefer "hands-on, interactive, and peer-based training" (p. 363), which reflects generational differences that may exist between principals and teachers when it comes to teacher leadership development. These differences may be more readily detected and embraced when strong and open relationships exist and transparency is the norm. Ultimately, it is the responsibility of school leaders to create positive and growth-oriented school climates where teachers are motivated to learn, given autonomy to explore and innovate, and empowered to develop professionally.

\section{Vignette 3: Harnessing Teacher Passions to Create Teacher and Student Opportunity}

Given the impact of intrinsic motivation on a teachers' willingness to go above and beyond, school leaders who know teachers and understand their passions are better positioned to create leadership opportunities for teachers, which can ultimately advance the school's mission. As principal at a large K-12 school, I came to know an incredibly humble, reserved, and effective third grade teacher and learned of her passion for gardening and preserving monarch butterflies. She excitedly shared with me one morning over coffee that her backyard was strategically planted with native plants and flowers as an important source of nectar for butterflies, and she elaborated that milkweed was planted to feed the monarch caterpillars. I asked her if she would be interested in sharing this passion with her students by creating a similar garden at the school, and she jumped at the opportunity! I worked with her as she developed a proposal and budget to include details around cost, materials, location, and logistics for building and maintaining the garden, and we devised curricular connections. This was more than the creation of a butterfly garden: It was an opportunity to engage a teacher, build community, enhance student experiences, and develop a teacher leader.

With passion and excitement driving her desire for the project, I intentionally took time to consider a school leader's posture for such projects, including less exciting but necessary aspects of budget allocations, risk management, and work 
order preparations. We also discussed how the project could be connected to the school's mission, ways we could involve the whole school, and how to leverage this project to promote our school in the broader community. The butterfly garden was absolutely spectacular and exceeded everyone's expectation. It even had official signage, providing visitors with information about monarch butterflies and the process the grade three classes undertook to make the butterfly garden a reality. The teacher and her students were so proud of their collective accomplishment, and through reflection and dialogue along the way, the teacher learned much about the power and potential of leadership that can be developed through collaboration with her school principal.

An effective school leader models best practice in plain sight for students, teachers, and parents, but so much more happens behind closed doors that teachers otherwise might not be aware of the complexities of school leadership. By empowering teachers to take part in some of those experiences and involving them in decision-making in the greater context of a school's competing priorities, teachers are able to gain a broader understanding of the larger context. It is critical, then, to take time to debrief and discuss why particular decisions were made or actions taken, and then solicit feedback from teachers for their perspective. Motivation, empowerment, and autonomy are all critical components that drive opportunities to develop teacher leaders.

\section{TEACHER LEADERSHIP}

Studies related to teacher leadership have been on the rise in recent years as schools have endeavored to reformat instructional practices based on the input of expert teachers. Providing teacher leaders with the opportunity to take on roles and responsibilities outside of the traditional classroom develops a learning culture that drives institutional improvement (Cansoy \& Parlar, 2017; Demir, 2015; Teasley, 2017). Teacher leadership, however, is largely dependent on the support of school administration. To take advantage of teachers' expertise and experiences, school leaders must provide professional development opportunities, give time for dialogue, and assign responsibility for implementing innovative new ideas. Further, it is critical that school leaders allow time and opportunity to experiment with new approaches to implementing teacher leadership training that will result in leadership capacity. If teachers are not able to occasionally falter without persecution, then the inherent risk involved with implementing new ideas prevents trust development and thereby interferes with the development of true teacher leadership (Cansoy \& Parlar, 2017; Teasley, 2017).

Teasley (2017) reasoned that the organizational climate of a school can either build cohesion and strength or erode the integrity and effectiveness of the learning that takes place. Whether teachers hide behind closed doors and work with their students in isolation or collaborate to ensure best practices are implemented is largely up to school administration. The principal's tone, expectations, mutual trust, and leadership style either encourages or suppresses the development of teacher leadership. As suggested by Sahin (2011), the essential responsibility of a school leader is to develop and sustain a positive school climate given the powerful influence it has on the teaching and learning that takes place in classrooms. Supporting and encouraging teacher leadership is conducive to increased morale, student learning, collegiality, and joy in schools (Cansoy \& Parlar, 2017; Carswell, 2018, Demir, 2015; Teasley, 2017). School leaders must encourage and develop teacher leaders in order to ensure optimal effectiveness in pedagogical practice and the development of future school leaders.

A recently retired superintendent of human resources shared how challenging it can be to develop the leadership competencies of classroom teachers and insert them back into schools as principals. He explained that his school district had less than a thousand elementary teachers in 50 schools and that maintaining principals for each of the 50 schools from a relatively small pool of teachers was quite trying (P. Warner, personal communication, October 12, 2019). On a similar note, the National Association of Secondary School Principals research confirmed the quandary of finding a sufficient quantity and quality school leaders: "The demand for employment of elementary, middle, and high school principals will grow by 6 percent nationwide by the year 2022" (NASSP, n.d.) while the National Association of Elementary School Principals report declared, "There are serious cracks in the leadership pipeline that have led to principal shortages" (NAESP, 2019). Actively promoting leadership opportunities for teachers will help to curb these trends.

Current leadership development models promote relying on external opportunities such as seminars, conferences, online leadership development courses, or even national, state or provincial leadership development programs. But why are leaders reluctant to take on leadership development themselves in the context in which teachers are working? By embedding leadership development into the ethos of a school through identification of teachers' unique talents, passions, and experiences, school leaders are well-positioned to boost teacher engagement, enhance school climate, and create opportunity for students that may not otherwise exist. 
In my experience, mentorship is most effective when centered around authentic and meaningful experiences designed to engage the mentee's personal or professional interests. The purpose and objectives must be clear to those involved. When these opportunities arise, take time to engage and include teacher leaders in reflective dialogue: before, during, and after implementation. Discuss what went right, what went wrong, and what could have been done differently or better if we possessed the power to turn back time. According to Rogers (2001), reflection is defined as "a cognitive and affective process or activity that (1) requires active engagement on the part of the individual; (2) is triggered by an unusual or perplexing situation or experience; (3) involves examining one's own responses, beliefs, and premises in light of the situation at hand; and (4) results in integration of the new understanding into one's experience" (p.41). By integrating the reflective experience into teacher leadership development, teacher leaders will explore and learn through the stages of Kolb's (1984) Learning Cycle: having a concrete experience followed by observation of and reflection on that experience, which leads to the formation of abstract concepts (analysis) and generalizations (conclusions), which are then used to test the hypothesis in future situations, resulting in new experiences. Ongoing dialogue and reflection between mentor and mentee are essential as teacher leaders journey toward new understandings of leadership principles and the application thereof.

\section{Vignette 4: Mentorship is a Two-Way Street}

Reflecting on my contributions as a school leader, one of my most valued and fulfilling experiences was while I served as a teacher mentor. Among an outstanding group of teachers in a large K-12 school, there was an incredible second grade teacher who stood out as one of those influential informal leaders who principals value so much. When prospective families or school visitors would tour, my default was to take them into specific classrooms that presented well to outsiders (not to suggest that they were better teachers - they just happened to be great teachers who kept their classrooms organized and aesthetically pleasing). After a year or so, this second-grade teacher asked to speak with me privately. In a direct yet respectful way, she revealed that she was upset that I rarely toured families through her classroom, and she wanted to know why. I shared my rationale: despite being a master teacher, other teachers' classrooms simply showed better. Rather than becoming defensive, she authentically reflected on my feedback. In the days following, she asked for help to create a classroom space that would flow better for students and present an inviting look at the class in action. Summer began a few weeks later, and together, we worked to improve the layout and design of her classroom space. We consulted a book about brain research - one chapter in particular addressed classroom design and its influence on student learning. From this experience, I learned that not only was she a great teacher and learner, she was unafraid to share her opinion or feelings, had the fortitude to ask difficult questions, and demonstrated an openness to hearing feedback and responding in a productive way. Knowing this, I was eager to work with her to develop leadership capacity both informally and formally. A year later when the vice principal position opened, I was thrilled to have her, a known entity, available and able to shift into a more formal leadership role. Shortly after her appointment as vice principal, we traveled to a conference together and spent time discussing our beliefs and ideas, and we ultimately shared one another's vision as to how we could most effectively work together to serve our teachers and students. Several more years of leading and learning together, and it was time for me to move along to my next role. After an extensive search for my replacement, and following the consideration of numerous external applicants, the same vice principal I had mentored and worked alongside was appointed as my successor. Her accomplishments were significant, and when I reached out to ask her perspective on our time together, she wrote:

Each opportunity for growth created reflective moments to further develop my leadership toolbox. The collaborative and open way in which you operated as a school leader allowed me to look at a situation from all sides and gain a broad sense of the impact decisions can have. Ongoing dialogue and reflection were essential in the latter part of my journey to school leadership, and I am grateful to have had the opportunity to hone my skills with a safety net in place before starting on my own (S. Spivak, personal communication, October 29, 2019).

Participation in real-world and purposeful leadership experiences beyond typical classroom responsibilities allows teacher leaders to gain genuine school leadership experiences firsthand. This includes admissions decisions, curricular committees, interview teams, project management, leading a student organization or team, review committees, or event leadership. But it is important to reiterate that simply participating is not enough; the identification of leadership capacity in these roles must be reflected upon and discussed. Only then can teachers have a better sense of how empowering it can be to participate in processes that lead to the improvement of school climate and the growth of the institution as a whole. 


\section{Vignette 5: A Concluding Reflection}

July 1, 2006 was my first day as a school principal. After looking back years later, my first boss did right by me: He allowed me to learn through real-world struggle and occasional failure. I would meet with him in his giant office, share an earth-shattering idea I had, and he would send me on my way with a pat on the back. An hour or day or week or month later, I would gravitate back to his office, sitting in his wingback chair, tail between my legs, trying to unpack what went wrong. Invariably, he stated in one form or another: “...saw that coming." When I asked why, if he saw it coming, he allowed (even encouraged!) me to proceed with whatever it was I had planned, he said something like "I could've told you, but that would be too easy." Lessons in leadership oftentimes come with the experience of failure and a few lumps along the way. All these years later, I have the upmost respect for my former boss: his uncanny yet effective leadership and his willingness to serve as my mentor and share the wisdom he had gained through years of experience. The foundation of our stout relationship, and the forthright and transparent way in which we worked together, afforded opportunities for me to grow as a leader through both success and failure. The autonomy and empowerment he extended his young mentee motivated me to lead to the upmost of my ability. Through reflection and dialogue, mentorship and modelling, I learned important leadership principles that I now take pride in sharing with others.

As I continue to grow in my capacity and confidence as a school leader, I came to realize that the observations I had made in my classroom are echoed in a school-wide setting: that both students and teachers who want to come to class (most days, anyway) achieve greater success. Students and teachers alike thrive in joyful and engaging climates where genuine relationships are in place, opportunities to grow and learn exist, and leadership capacity is nurtured - even when inevitable failures occur along the way.

\section{CONCLUSION}

School leaders would be remiss in leaving to chance the important task of identifying, encouraging, motivating, and mentoring the leadership capacity of teachers. Through the intentional development of authentic relationships, leaders who learn about teachers' passions, aspirations, and experiences are better equipped to encourage them to contribute beyond the domain of their classrooms, improve school climate, and provide enriching student programming. It is critical for leaders to construct positive and joyful school climates, foster and model collaboration, and understand what motivates teachers to grow professionally. This, in turn, contributes significantly to the advancement of the mission of the organization as a whole. Ultimately, the school leader's efforts are rewarded with an overwhelming sense of fulfillment that comes through watching teachers grow and develop into the kind of leader they are capable of becoming. As school leaders, developing the leadership capacity of teachers should stand as one of our foremost priorities - an investment today that will pay enormous dividends for schools of tomorrow.

\section{REFERENCES}

Amabile, T., \& Kramer, S. (2007). Inner work life: Understanding the subtext of business performance. Harvard Business Review, 85(5), 72-83, 144.

Bayler, A., \& Özcan, K. (2012). Cultural adaptation of headmasters' transformational leadership scale and a study on teachers' perceptions. Eurasian Journal of Educational Research, 49, 103-128.

Cansoy, R., \& Parlar, H. (2017). Examining the relationship between school culture and teacher leadership. International Online Journal of Educational Sciences, 9(2), 310-322.

Carswell, M.A. (2018). Understanding leadership factors that contribute to positive, joyful, and engaging climates at independent schools. (Unpublished doctoral dissertation). Nova Southeastern University, Fort Lauderdale, FL.

Demir, K. K. (2015). The effect of organizational trust on the culture of teacher leadership in primary schools. Educational Sciences: Theory \& Practice, 15(3), 621-634.

Höög, J., Johansson, O., \& Olofsson, A. (2005). Successful principalship: The Swedish case. Journal of Educational Administration, 43(6), 595-606.

Hord, S. M. (2009). Professional learning communities. National Staff Development Council, 30(1), 40-43.

Kegan, R., Lahey, L., Fleming, A., Miller, M., \& Markus, I. (2013, March). The deliberately developmental organization. Retrieved from https://static1.squarespace.com/static/54541a13e4b0331fc2f2a0f7/t/550b6b72e4b0ff02510e1594/1426811762075/W2 G+What+is+a+DDO+Sept+2013+Copyrighted.pdf 
Kolb, D.A. (1984). Experiential learning: Experience as the source of learning and development (Vol. 1). Englewood Cliffs, NJ: Prentice-Hall.

Ludwick, P. (2006). Manage the relationships, the team will manage the work. Journal of Housing and Community Development, 63(3), 38-41.

National Association of Elementary School Principals. (2019). AASA, NAESP launch national aspiring principals academy. Retrieved from https://www.naesp.org/content/aasa-naesp-launch-national-aspiring-principals-academy

National Association of Secondary School Principals (n.d.). Principal shortage. Retrieved from https://www.nassp.org/policy-advocacy-center/nassp-position-statements/principal-shortage/Ontario Ministry of Education (2014). Capacity building series (Vol. 38).

Preskill, S. and Brookfield, S. D. (2009). The essence of learning leadership. San Francisco, CA: Jossey-Bass.

Rogers, R. R. (2001). Reflection in higher education: A concept analysis. Innovative Higher Education, 26(1), $37-57$.

Sagnak, M. (2016). Participative leadership and change-oriented organizational citizenship: The mediating effect of intrinsic motivation. Eurasian Journal of Educational Research, 62, 199-212.

Sahin, S. (2011). The relationship between instructional leadership style and school culture (Izmir case). Kuram Ve Uygulamada Egitim Bilimleri, 11(4), 1920-1927.

Seipert, K., \& Baghurst, T. (2014). Contrasting work values of baby boomers and generation X rural public school principals. Public Administration Quarterly, 38(3), 347-370.

Shindler, J., Jones, A., Williams, A. D., Taylor, C., \& Cardenas, H. (2016). The school climate - student achievement connection: If we want achievement gains, we need to begin by improving the climate. Journal of School Administration Research and Development, 1(1), 9-16.

Shwu Ming, W. (2015). Development and application of the measures of school value, teacher autonomy, and teacher motivation. New Educational Review, 39(1), 240-250.

Teasley, M. (2017). Organizational culture and schools: A call for leadership and collaboration. Children \& Schools, 39(1), 3-5.

White, D. W., \& Lean, E. (2008). The impact of perceived leader integrity on subordinates in a work team environment. Journal of Business Ethics, 81(4), 765 -778.

M. ADAM CARSWELL, Ed.D., is an elementary school leader and former faculty in the Master of Education program and an Educational Developer in the Leadership and Excellence in Academic Development (LEAD) Division in the Department of Educational Services at St. George's University, Grenada, West Indies. As a scholar-practitioner with two decades of experience as both teacher and principal, he developed a particular interest in teacher leadership development and the importance of creating joyfully engaging school climates for students and teachers. Email: adam.carswell@lkdsb.net 